\title{
Unipolar Mania: A Particular Aspect of Bipolar Disorder in Tunisia
}

\author{
Badii Amamou, Wafa Chebbi, Myriam Allegue, Ahmed Mhalla, Ferid Zaafrane, Lotfi Gaha \\ Department of Psychiatry, University Hospital of Monastir (EPS Fattouma Bourguiba), Monastir, Tunisia
}

\begin{abstract}
Objective: Unipolar mania is a clinical reality in our daily practice. Many authors suggested that bipolar patients can have only manic episodes without depressions. These findings lead us to explore more this particularity.

Methods: We conduct a retrospective, descriptive and comparative study including 173 patients, followed for bipolar disorder type I, according to the Diagnostic and Statistical Manual of Mental Disorders fifth edition criteria, during the period between January 2008 and December 2015. Two groups were identified. The first one was composed of 98 patients who had presented only manic episodes. The second group contained the rest of the sample. Unipolar mania was defined as the presence of three or more manic states without a depressive episode during the period of the study.

Results: One hundred seventy three patients were included in the study. The average age of the sample was 43 years old. The first episode was manic in 129 patients (74.6\%). The dominant polarity was manic in $90.8 \%$ of the cases. Seasonal characteristic and psychotic symptoms were observed in respectively $11.0 \%$ and $53.2 \%$ of the sample. Rapid cycling evolution was observed among $2.3 \%$ of patients. The unipolar manic profile accounted for $56.6 \%$ of the population. This result is equivalent to an annual incidence of $8 \%$. Comparing the two groups, we did not find a significant difference concerning the sociodemographic and clinical variables except for the number of suicide attempts $(p=0.014)$.

Conclusion: Our study shows that unipolar mania is clinical evidence. More studies should be conducted in order to understand its nosological and psychopathological foundations.
\end{abstract}

KEY WORDS: Unipolar mania; Bipolar disorder; Recurrent mania.

\section{INTRODUCTION}

The origins of bipolar disorder (BD) trace back to the 19th century, when it was described in the studies of Grinsinger, Baillarger and Falret. ${ }^{1)}$ However, it was Kraepelin ${ }^{2)}$ who had associated manic, depressive and mixed states into one category: manic depressive disorder. This classification has revolutionized psychiatry and the term of BD had appeared in the Diagnostic and Statistical Manual of Mental Disorders in its third edition (DSM III). ${ }^{1)}$ $\mathrm{BD}$ is known to be a recurrent mood disorder characterized by the alternation of expansive and depressive

Received: April 11, 2017 / Revised: May 4, 2017

Accepted: May 11, 2017

Address for correspondence: Badii Amamoum, MD

Department of Psychiatry, University Hospital of Monastir (EPS Fattouma Bourguiba), Avenue Farhat HACHED 5000, Monastir, Tunisia

Tel: +216-98475488, Fax: +216-73460678

E-mail: amamoubadii@hotmail.fr

ORCID: https://orcid.org/0000-0001-5079-6252 mood states separated by free intervals. However, Leonhard ${ }^{3)}$ had individualized two forms: bipolar and unipolar forms. The bipolar form is characterized by the recurrence of opposed episodes in the same individual, while the unipolar form consists of the recurrence of an only type of mood disorder either depression or mania. Neele was also interested in the genetic basis of this concept and found a distinction between the inheritability of unipolar mood disorders and manic-depressive disorder. ${ }^{4,5)}$ Although the new classification of 5th edition of DSM (DSM 5) did not individualize unipolar mania, this entity retains its relevance for many authors. ${ }^{6)}$ The prevalence of unipolar mania is variable from one study to another. It represents between 20 to $27 \%$ of BD in some studies ${ }^{7,8)}$ and only $5 \%$ to $9 \%$ in other ones. ${ }^{6)}$ These findings lead us to explore this particular aspect. From this perspective, the aim of our study was to determine the incidence of unipolar mania in diagnosed bipolar patients and its characteristics.

(ㄷ) This is an Open-Access article distributed under the terms of the Creative Commons Attribution Non-Commercial License (http://creativecommons.org/licenses/by-nc/4.0) which permits unrestricted non-commercial use, distribution, and reproduction in any medium, provided the original work is properly cited. 


\section{METHODS}

\section{Nature of the Study}

We conducted a retrospective, descriptive and comparative study in psychiatric department of University Hospital Fattouma Bourguiba in Monastir, Tunisia during the period between January 2008 and December 2015.

\section{Study Population}

We included 173 hospitalized patients who were followed for a BD type I according to DSM 5 criteria for at least one year. ${ }^{9)}$ Patients who presented an episode due to a medical affection or an antidepressant treatment as well as those who were lost for sight were excluded from the study. We identified two groups. The first group was composed of patients who only presented manic episodes defining the unipolar mania profile. The second group was composed of the rest of the subjects.

\section{Data Collection}

Data were collected from interviews with patients and their medical records using to pre-established questionnaire exploring sociodemographic, clinical and therapeutic charactarestics.

\section{Incidence of Unipolar Mania}

According to recent studies, we defined unipolar mania as the presence of three or more manic states without a depressive episode during the period of the study. Then, we calculated the incidence of unipolar mania. Since the criterion of judgment is recurrent in the disease, our study will take in consideration the prevalence of unipolar mania.

\section{Statistical Procedure}

All data was analyzed using IBM SPSS for Widows software package (ver. 21.0; IBM Co., Armonk, NY, USA). We used Pearson's chi-square $\left(\chi^{2}\right)$ tests to compare the variables between the two groups. The significant level of statistical was set at $p \leq 0.05$.

\section{RESULTS}

The sample was composed of 173 patients whose average age was $43.3 \pm 12.2$ years old and predominant gender was male (68.2\%). Two percent of patients were illiterate and $49.1 \%$ had a secondary level education. We found that $34.1 \%$ were unemployed and $50.3 \%$ were unmarried. The average age of onset was $24.9 \pm 8.2$ years old and it was considered as early (before 18 years old) in 41 patients and late (after 40 years old) in 9 patients. The average duration of the disease was $17.9 \pm 10.2$ years old. The first episode was manic in 129 patients (74.6\%). A dominant manic polarity was found in $90.8 \%(n=157)$ of

Table 1. Sociodemographic and clinical characteristics of the sample

\begin{tabular}{|c|c|c|c|c|}
\hline Characteristic & G1 $(n=101)$ & G2 $(n=72)$ & Sample $(n=173)$ & $p$ value \\
\hline Age (yr) & $41.7 \pm 12.8$ & $45.4 \pm 10.9$ & $43.3 \pm 12.2$ & 0.05 \\
\hline \multicolumn{5}{|l|}{ Sex } \\
\hline Male & $71(70.3)$ & $47(65.3)$ & $118(68.2)$ & \multirow[t]{2}{*}{0.51} \\
\hline Famale & $30(29.7)$ & $25(34.7)$ & 55 (31.8) & \\
\hline \multicolumn{5}{|l|}{ Professional status } \\
\hline Unemployed & $34(33.7)$ & $25(34.7)$ & $59(31.4)$ & \multirow[t]{2}{*}{1} \\
\hline Employed & $67(66.3)$ & $47(65.3)$ & $114(68.6)$ & \\
\hline \multicolumn{5}{|l|}{ History of suicide attempts } \\
\hline Yes & $5(5.0)$ & $16(22.2)$ & $21(12.1)$ & \multirow[t]{2}{*}{$<0.001$} \\
\hline No & 96 (95.0) & $56(77.8)$ & $152(87.9)$ & \\
\hline Average number of suicide attempts & $0.13 \pm 0.7$ & $0.49 \pm 1.15$ & $0.28 \pm 0.92$ & 0.014 \\
\hline Addictive behavior & $8(7.9)$ & $9(12.5)$ & $17(9.8)$ & 0.44 \\
\hline Age on onset (yr) & $24.23 \pm 8.37$ & $26 \pm 8.08$ & $24.95 \pm 8.2$ & 0.17 \\
\hline Mean duration of the disease (yr) & $17.1 \pm 10$ & $19.1 \pm 10.38$ & $17.94 \pm 10.17$ & 0.2 \\
\hline Average number of hospitalizations & $5.1 \pm 4.1$ & $5.34 \pm 3.83$ & $5 \pm 4$ & 0.69 \\
\hline Seasonal characteristic & $12(11.9)$ & $7(9.7)$ & $11(6.4)$ & 0.8 \\
\hline Psychotic characteristics & $60(59.4)$ & $32(44.4)$ & $92(53.2)$ & 0.06 \\
\hline Rapid cycling & $1(1)$ & $2(2.8)$ & $4(2.3)$ & 0.57 \\
\hline
\end{tabular}

Values are presented as mean \pm standard deviation or number (\%). 
cases, against depressive polarity in only $9.2 \%(n=16)$ of cases. The seasonal characteristic and psychotic symptoms were observed in respectively $11.0 \%$ and $53.2 \%$ of subjects. The patients of $2.3 \%$ had rapid cycling evolution.

Subsequently, we have compared two groups. The first group was composed of patients with three or more manic episodes in the absence of depression, called unipolar mania. Ninety-eight cases of unipolar mania in 7 years were observed. This unipolar manic profile accounted for $56.6 \%$ of the population. This result is equivalent to an annual incidence of $8 \%$. The two groups were matched for age and sex and were comparable for sociodemographic and clinical characteristics. A significant difference was only observed concerning the history and the average number of suicide attempts $(p<0.001 ; p=0.014)$.

The principles characteristics of the sample and its two groups are reported in Table 1.

\section{DISCUSSION}

\section{Incidence of Unipolar Mania}

Among 173 patients who had participated in this study, 98 had only manic episodes which correspond to $56.6 \%$ of the sample. In other words, more than half of the study population had unipolar mania profile which is considered as high. Similar results were found in other studies: Dakhlaoui et al. ${ }^{10)}$ found that $65.3 \%$ of bipolar patients had relapsed only on the manic mode and they did not have any depressive episode, while Aghanwa ${ }^{11)}$ reported a rate of $47.2 \%$. In the most populous country in Africa, Nigeria, recurrent mania is considered as the rule and not the exception. ${ }^{12,13)}$ In the Indian subcontinent, it was observed that as recurrent mania were very common in BD. ${ }^{14)}$ Chinese study found a high prevalence of recurrent mania while depressions were rare. ${ }^{15)}$ In a prospective Tunisian study, $35.6 \%$ of 129 bipolar patients had only manic states which is lower than our results but is not negligible either. ${ }^{16)}$ On the contrary, lower percentages were reported in Shulman, Perugi or Yazici's studies. ${ }^{17,18)}$ European studies found lower levels of unipolar mania between $12 \%$ to $25 \%{ }^{10)}$ A majority of bipolar patients from Spain, USA or Germany spend more than the half of the time in depressive states than in the manic states. ${ }^{19)}$

This diversity of results is probably due to the use of different criteria for the definition of the disorder (number of episodes, duration of follow-up, etc.) and the prospective or retrospective nature of the studies. ${ }^{10,11,13,14,17,18,20-29)}$ Indeed, the position of unipolar mania in psychiatric nosology is still controversed. The DSM in its 4th and 5th editions and the International Classification of Diseases, 10th edition (ICD-10) include unipolar mania within the diagnostic entity of BD. ${ }^{9,30,31)}$ Since 1990, the number of manic episodes in the definition of unipolar mania has increased from 2 to 4 or more without a history of depression. ${ }^{11,14,28)}$ In addition, there was no consensus on the

Table 2. Different definitions and prevalence of unipolar mania in literature

\begin{tabular}{|c|c|c|c|}
\hline \multirow{2}{*}{ Reference } & \multirow{2}{*}{ Prevalence (\%) } & \multicolumn{2}{|l|}{ Definition } \\
\hline & & Mania & Depression \\
\hline Perris and d'Elia, 1966 20 ) & 4.5 & $\geq 1$ & 0 \\
\hline Abrams and Taylor, $1974^{21)}$ & 28.0 & Not defined & 0 \\
\hline Nurnberger et al., $1979^{22)}$ & 15.7 & $\geq 1$ hospitalization & 0 hospitalization \\
\hline Abrams et al., $1979^{23)}$ & 18.0 & 2 & 0 \\
\hline Perris, $1982^{17)}$ & 1.1 & 1 & 0 \\
\hline Pfohl et al., $1982^{24)}$ & 35.2 & 1 & 0 \\
\hline Rao et al., 1982 & 2.7 & 1 & 0 \\
\hline Rao and Madhavan, $1983^{25)}$ & 12.0 & 1 & 0 \\
\hline Srinivasan et al.,1985 & 40.0 & 3 & 0 \\
\hline Makanjoula, 1985 & 53.0 & 2 & 0 \\
\hline Margoob and Dutta, $1988^{27)}$ & 42.0 & Not defined & Not defined \\
\hline Khanna et al., $1992^{14)}$ & 44.0 & 4 & 0 \\
\hline Avasthi et al., 1996 & 6.5 & 3 & 0 \\
\hline Aghanwa, $2001^{11)}$ & 47.2 & 3 (hypo-mania included), duration of the disease at least $4 \mathrm{yr}$ & 0 \\
\hline Yazici et al., 2002 $2^{18)}$ & 16.3 & 4 , at least 4 yr of follow & 0 \\
\hline Perugi et al., 2007 29$)$ & 21.8 & 3 , duration of the disease at least $10 \mathrm{yr}$ & 0 \\
\hline Dakhlaoui et al., $2008^{10)}$ & 65.3 & 2 , at least $5 \mathrm{yr}$ of follow & 0 \\
\hline
\end{tabular}


duration of the disease. Aghanwa ${ }^{11)}$ defined unipolar mania as " 3 episodes of mania or hypomania and at least 4 years of disease progression" while Yazici et al. ${ }^{18)}$ considered it as " 4 or more episodes of mania and at least 4 years of follow-up without any depressive episode." The different definitions and prevalence of unipolar mania are represented in the Table 2.

The high incidence of unipolar mania found in our study can be explained by the differences in the expression of bipolarity between the West and the rest of the world. ${ }^{15)}$ A recent intercultural study reported that unipolar mania was three times more frequent in Tunisia than in France. ${ }^{32)}$ This suggests the existence of factors that may affect the expression of the disease. One of these factors is the photoperiod and seasonality. Sunlight and latitude could be determinant factors in the expression of thymic states. ${ }^{19)}$ Now, it is recognized that circadian rhythm abnormalities have an important role in the course of the trouble. We noticed that countries in where mania was predominant were those having a greater ambient sunlight. ${ }^{19)}$ Assumptions suggest that CLOCK3111 T/C $\mathrm{C} / \mathrm{C}$ allele is associated to a higher rate of recurrence. ${ }^{33)}$ This hypothesis could explain why manic states are predominant in tropical and Mediterranean places. Another suggestion can be advanced and consists on the fact that nutritional habits in Mediterranean countries that are rich in omega-3 and dopaminergic nutriments could protect patients from developing depressions. ${ }^{15)}$ Moreover, in our country, depressive episodes of moderate intensity are probably underestimated because of the high tolerance to these symptoms by families. ${ }^{15)}$ According to that, the low rate of depression, found in our study, could be linked to the cultural and religious determinants of the Tunisian society. The "non-recognition" of depression, the stigmatization of mental illness and the tolerance of the entourage could mask a depressive episode.

\section{Sociodemographic and Clinical Profile of Unipolar Mania}

Concerning the sociodemographic and clinic profile, patients with unipolar mania did not present significant differences in various parameters apart from the suicide profile. Both the two groups were comparable at the sociodemographic characteristics (age, sex, professional and unmarried status) but also at the clinical aspect (age on onset, duration of the disease, number of hospitalizations, addictive behavior, seasonal and psychotics characteristics, rapid cycling). The studies conducted by Dakhlaoui et al. ${ }^{10)}$ or Aghanwa ${ }^{11)}$ did not find, globally, any differences between the two groups. This reinforces our results. Yet, three parameters were found significantly different in the study of Dakhlaoui et al. ${ }^{10)}$ The addictive behavior was twice higher in bipolar group, the average age of onset was earlier in unipolar group and the seasonal characteristic of the first-episode was considered as different. While unipolar group had their first episode in summer, the bipolar group started its disease in winter. These three parameters were not different in our groups of study. However, other studies have found significant correlation between unipolar mania and some variables such as the female gender, the earlier age at onset, the number of episodes, the occurrence of psychotic symptoms. ${ }^{14,24,34)} \mathrm{A}$ less occurrence of rapid cycling phenomenon was yet associated to manic states. ${ }^{18)}$ The only significant difference found in our study was the number of suicide attempts which was higher in the bipolar group. This can be explained by the occurrence of depressive episodes that are characterized by the emergence of ideas of death related to pessimism and despair.

It is important to point out the limits of our study. First, the retrospective nature of our study can be a recall bias. Collecting data from medical files does not allow meticulous examination of the course of the trouble. The number of participants is still reduced and interests only our psychiatric department. Furthermore, depressions with moderate intensity may have been underreported.

In conclusion, unipolar mania appears to be clinical evidence in our socio-demographic context. And the unipolar manic profile accounted for $56.6 \%$ of our population. This result is equivalent to an annual incidence of $8 \%$. Many other studies confirmed this finding, especially in tropical and Mediterranean regions. European and American studies does not find similar results as for them, this entity is still contested. Withal, our study raises questions about the place and functions of the inseparable mania of depression and may lead us to reconsider the nosological and psychopathological foundations of mood disorders. Some hypotheses are advanced to explain this variety in the expression and the course of BD. Yet, further studies are still needed to explore this side of the disease. 


\section{Acknowledgments}

The authors would like to acknowledge the participants of this study. This is a non funded study.

\section{REFERENCES}

1. Bourgeois ML, Gay C, Henry C, Masson M. Les troubles bipolaires. Cachan:Lavoisier;2014.

2. Kraepelin E. Psychiatrie: ein kurzes lehrbuch für studierende und Ärzte. 8th ed. Leipzig:von Barth Verlag; 1920.

3. Leonhard K. The classification of endogenous psychoses. New York:Irvington Publishers, distributed by Halsted Press; 1979.

4. Muneer A. Staging models in bipolar disorder: a systematic review of the literature. Clin Psychopharmacol Neurosci 2016;14:117-130.

5. Kim W, Woo YS, Chae JH, Bahk WM. The diagnostic stability of DSM-IV diagnoses: an examination of major depressive disorder, bipolar I disorder, and schizophrenia in Korean patients. Clin Psychopharmacol Neurosci 2011;9:117-121.

6. Vignat JP, Prieto N. [Mania and epidemiology]. Psychiatrie française 2001;32:105-117. French.

7. de Zélicourt M, Dardennes R, Verdoux H, Gandhi G, Papatheodorou ML, Edgell ET, et al. [Bipolar I disorder in France: prevalence of manic episodes and hospitalisation-related costs]. Encephale 2003;29:248-253. French.

8. Kessler RC, McGonagle KA, Zhao S, Nelson CB, Hughes M, Eshleman $\mathrm{S}$, et al. Lifetime and 12-month prevalence of DSM-III-R psychiatric disorders in the United States. Results from the National Comorbidity Survey. Arch Gen Psychiatry 1994;51:8-19.

9. American Psychiatric Association. Diagnostic and Statistical Manual of Mental Disorders, fifth ed (DSM-5). Washington, D.C.:American Psychiatric Publishing;2013.

10. Dakhlaoui O, Essafi I, Haffani F. /Clinical particularism of bipolar disorder: unipolar mania. About a patient's study in Tunesia]. Encephale 2008;34:337-342. French.

11. Aghanwa HS. Recurrent unipolar mania in a psychiatric hospital setting in the Fiji Islands. Psychopathology 2001;34:312317.

12. Makanjuola RO. Manic disorder in Nigerians. Br J Psychiatry 1982;141:459-463.

13. Makanjuola RO. Recurrent unipolar manic disorder in the Yoruba Nigerian: further evidence. Br J Psychiatry 1985;147: 434-437.

14. Khanna R, Gupta N, Shanker S. Course of bipolar disorder in eastern India. J Affect Disord 1992;24:35-41.

15. Douki S, Ben Zineb S, Nacef F. [Bipolar disorder in Southern countries]. Encephale 2005;31:58. French.

16. Shulman KI, Tohen M. Unipolar mania reconsidered: evidence from an elderly cohort. Br J Psychiatry 1994;164:547549 .
17. Perris C. The distinction between bipolar and unipolar affective disorders. In: Paykel ES, editor. Handbook of affective disorders. London:Churchill Livingstone; 1982. p. 45-68.

18. Yazici O, Kora K, Uçok A, Saylan M, Ozdemir O, Kiziltan E, et al. Unipolar mania: a distinct disorder? J Affect Disord 2002;71:97-103.

19. Rangappa SB, Munivenkatappa S, Narayanaswamy JC, Jain S, Reddy YC. Predominant mania course in Indian patients with bipolar I disorder. Asian J Psychiatr 2016;22:22-27.

20. Perris C, d'Elia G. A study of bipolar (manic-depressive) and unipolar recurrent depressive psychoses. X. Mortality, suicide and life-cycles. Acta Psychiatr Scand Suppl 1966;194:172189.

21. Abrams R, Taylor MA. Unipolar mania: a preliminary report. Arch Gen Psychiatry 1974;30:441-443.

22. Nurnberger J Jr, Roose SP, Dunner DL, Fieve RR. Unipolar mania: a distinct clinical entity? Am J Psychiatry 1979;136:14201423.

23. Abrams R, Taylor MA, Hayman MA, Krishna NR. Unipolar mania revisited. J Affect Disord 1979;1:59-68.

24. Pfohl B, Vasquez N, Nasrallah H. Unipolar vs. bipolar mania: a review of 247 patients. Br J Psychiatry 1982;141:453-458.

25. Rao AV, Madhavan T. Depression and suicide behaviour in the aged. Indian I Psychiatry 1983;25:251-259.

26. Srinivasan K, Ray R, Gopinath PS. Unipolar mania - a separate entity? Indian I Psychiatry 1985;27:321-324.

27. Margoob MA, Dutta KS. 10-15 years retrospective study of 50 patients of MDP for seasonal variations. Indian J Psychiatry 1988;30:253-256.

28. Avashthi A, Sharma A, Gupta N, Kulhara P, Varma VK. Seasonality and unipolar recurrent mania: preliminary findings from a retrospective study. Indian I Psychiatry 1996;38: 236-239.

29. Perugi G, Passino MC, Toni C, Maremmani I, Angst J. Is unipolar mania a distinct subtype? Compr Psychiatry 2007;48: 213-217.

30. American Psychiatric Association. Diagnostic and Statistical Manual of Mental Disorders, fourth ed (DSM-IV). Washington, D.C.: APA;1994.

31. World Health Organization. The ICD-10 classification of mental and behavioural disorders: clinical descriptions and diagnostic guidelines. Geneva:WHO;1992.

32. Douki S, Nacef F, Triki T, Dalery J. [Crosscultural aspects of bipolar disorder: results of a comparative study between French and Tunisian patients]. Encephale 2012;38:194-200. French.

33. Benedetti F, Serretti A, Colombo C, Barbini B, Lorenzi C, Campori $\mathrm{E}$, et al. Influence of CLOCK gene polymorphism on circadian mood fluctuation and illness recurrence in bipolar depression. Am J Med Genet B Neuropsychiatr Genet 2003; 123B:23-26.

34. Solomon DA, Leon AC, Endicott J, Coryell WH, Mueller TI, Posternak MA, et al. Unipolar mania over the course of a 20-year follow-up study. AmJ Psychiatry 2003;160:2049-2051. 